\title{
Multi-model Software Process Improvement based on C2M and MR- MPS-SW Models
}

\author{
Jeferson K. M. Vieira ${ }^{1,2 *}$, Ivaldir H. de Farias Jr ${ }^{3}$, Hermano P. de Moura ${ }^{2}$, Dennis Sávio Martins da Silva ${ }^{4}$
}

\author{
${ }^{1}$ Federal University of Ceará, Campus Quixadá, Ceará, BRAZIL \\ ${ }^{2}$ Federal University of Pernambuco, Informatic Center, Pernambuco, BRAZIL \\ ${ }^{3}$ University of Pernambuco, Campus Garanhuns, Pernambuco, BRAZIL \\ ${ }^{4}$ Federal University of Piauí, Piauí, BRAZIL \\ *Corresponding Author: jefersonkenedy@ufc.br
}

Citation: Vieira, J. K. M., de Farias Jr, I. H., de Moura, H. and Sávio, D. (2020). Multi-model Software Process Improvement based on C2M and MRMPS-SW Models. Journal of Information Systems Engineering and Management, 5(4), em0127. https://doi.org/10.29333/jisem/8532

\begin{tabular}{|c|c|}
\hline ARTICLE INFO & ABSTRACT \\
\hline Published: 8 Sep. 2020 & $\begin{array}{l}\text { The pursuit of competitive advantage has boosted organizations to improve their development processes. With } \\
\text { this, a range of maturity models for software development processes has emerged on the market. In this sense, } \\
\text { research efforts have been increasingly necessary to understand how organizations should deal with the various } \\
\text { maturity models, given the heterogeneity of the characteristics of these models. In this context, this work aims to } \\
\text { propose a mapping between MR-MPS-SW and C2M models. The proposed mapping was reviewed and evaluated } \\
\text { by five experts with experience in software process improvement. This mapping allowed us to identify that } 82.2 \% \\
\text { of C2M practices with some type of coverage for the expected MR-MPS-SW results. Finally, it is possible to see that } \\
\text { the models here mapped are not conflicting, but rather complementary, with C2M being partially adherent to MR- } \\
\text { MPS-SW. }\end{array}$ \\
\hline
\end{tabular}

Keywords: maturity model, multi-model, C2M, MR-MPS-SW

\section{INTRODUCTION}

The spread of globalization followed by the competition on the world market has boosted organizations for continuous innovations and improvements for processes and products (BALDASSARRE et al., 2010). In this respect, Mirna et al. (2011) present the software process improvement as the most critical and important effort that any organization must target, regardless of having its team organized in a traditional or distributed way, to improve its software development process capacity.

Despite the wide range of improvement models, many companies tend to adopt more than one of them, because not always a simple model can completely accomplish their requirements (GARCIA et al., 2016). Still, according to Garcia et al. (2016), the major difficulty in implementing more than one model is that each one has a different type of structure, generating conflicts and misunderstandings concerning what will be implemented in the enterprise.

Among the process improvement models found in the market, it is worth highlighting the MR-MPS-SW (Software Reference Model) (SOFTEX, 2016b) and the C2M (Communication Maturity Model) (FARIAS JUNIOR, 2014). MR-MPS-SW is one of the models that make up the MPS.BR Program, defined by SOFTEX (2016b) as a long-term mobilizing program, which aims to increase the organization's competitiveness by improving its processes. On its turn, C2M appears as an emerging maturity model focused on communication. C2M was proposed aiming to improve the communication of distributed software development teams. This model was built based in the literature and empirical data and inspired by other maturity models, like CMMI-DEV, MR-MPS-SW, eSCM and Wave (LEITÃO JUNIOR et al., 2017; FARIAS JUNIOR et al., 2016).

MR-MPS-SW and C2M have distinct characteristics and objectives, however, companies may want the process improvement provided by MR-MPS-SW and, at the same time, seek for the communication improvement proposed by $\mathrm{C} 2 \mathrm{M}$. In this sense, the heterogeneous characteristics of the models require more research about dealing with many process models at a time (SAHIBUDDIN et al., 2018).

In light of this context, the research question guiding this work is: What is the C2M adherence level with MR-MPS-SW? Grounded in this problem, the main aim of this work is to present a mapping among the MR-MPS-SW and C2M maturity models. This paper presents in an extended way the results discussed in Vieira (2020).

According to Baldassarre et al. (2010), when companies decide to adopt multi-model improvement initiatives, they must be prepared to the challenges, taking advantage of the best practices in the best way possible. This study can support organizations 
wishing to implement the maturity models mapped here. One of the major benefits of constructing mappings among models is that they supply concrete and traceable information for origin approaches and can serve as a basis for multi-model evaluations (KELEMEN, 2013).

In addition to this Section, this paper is organized into other 6 Sections. In Section 2, the main concepts related to multi-model processes are presented. Section 3 describes the MR-MPS-SW and C2M models. Section 4 describes the methodology used to construct the mapping. The mapping and pair review results are presented in Sections 5 and 6 . Section 7 presents the main limitations and threats to the results of this research. Finally, Section 8 presents the concluding remarks.

\section{IMPROVEMENT OF MULTI-MODEL PROCESSES}

Organizations invest in process improvement aiming to reach higher quality in their products, in addition to obtaining qualifications required for public and international bidding (ARAUJO et al., 2015). Still, according to Araujo et al. (2015), although there are several process improvement models, to believe in any model defined thus far as a complete solution for process management in the IT context would be unwise.

According to Pardo et al. (2012), some factors can influence the use of multiple models, such as market niches for specific models, improvement of practices from legacy processes, business positioning, leverages or incorporation, process capacity improvement and business growth. The use of multi-model environments demands extensive knowledge about these models and their intersections so that the joint implementation does not generate redundant processes, as well as unnecessary efforts and costs (ARAUJO et al., 2015). For Mirna et al. (2011), maturity models are not mutually exclusive, even when offering exclusive features and addressing specific issues.

Organizations want to benefit from advantages from different models and representations (PELDZIUS; RAGAISIS, 2011), however, according to (Kelemen 2013), the simultaneous use of multiple approaches can bring problems, such as the identification and manipulation of different approaches with different structures, granularity, terminology, contents, size, and complexity. Organizations must fight against the complexity and difficulty of understanding and interpreting various models at the same time (PARDO et al., 2012).

As an effort to support organizations in the selection of a correct implementation of the improvements, the multi-model environments arise allowing to use the best practices from different reference models (MEIJA et al., 2016). To Araujo et al. (2015), efforts must be done to identify intersections and common parts between the models, creating a multi-model improvement solution.

Multi-model initiatives can be classified in Kelemen (2013): mapping, integration, and harmonization. Harmonization happens when characteristics from approaches with independent quality are aligned with each other (such characteristics can be, for example, structure or terminology). A multi-model initiative is called integration when, instead of having autonomous quality approaches, the approaches are unified in an "integrated" approach. Finally, the multi-model initiative is called mapping when specific parts from different quality approaches, like requirements or terminologies, are compared.

From the categorization of multi-model initiatives presented by Kelemen (2013), this research can be characterized as a mapping, since it concentrates on identifying and mapping requirements from two different quality approaches (C2M e MR-MPSSW).

Concerning the mapping of two or more models, many works have been done in this direction. Araujo et al. (2015) map MRMPS-SW with CERTICS. Peldzius and Ragaisis (2011) map CMMI-DEV with ISO/IEC 15504. Mello (2011) presents a mapping of the models MPS and CMMI-DEV. Garcia et al. (2016) maps CERTICS and CMMI-DEV. SOFTEX published, yet, three other mappings, from MR-MPS-SW to NBR ISO/IEC 29110-4-1:2012 (SOFTEX, 2012a), from MR-MPS-SW to MoProSoft (SOFTEX, 2012b) model and from MR-MPS-SW to CMMI-DEV v1.3 (SOFTEX, 2016).

\section{MR-MPS-SW AND C2M REFERENCE MODELS}

The Brazilian Software Process Improvement Program (Programa de Melhoria de Processo do Software Brasileiro - MPS.BR) aims at improving the software processes in Brazilian companies from all regions, at an affordable cost, focused mainly at micro, small and medium-sized enterprises. Rules are established for its implementation and evaluation, giving support and ensuring that MPS.BR is being applied consistently with its definitions (SOFTEX, 2016b). The MPS model is described following a guide format, composed of General Guide (MR-MPS-SW), Implementation Guides, Evaluation Guides and Acquisition Guide.

The General Guide has a general and detailed description of the Reference Model (MR-MPS-SW), its components and the common definitions necessary for its understanding and application. The Implementation Guide describes how to implement a given level of the MR-MPS-SW model. The Evaluation Guide reports the process and the MA-MPS evaluation method, the requirements for leader and adjunct assessors and assessment institutions. The Acquisition Guide describes the process of software acquisition and correlated services (SOFTEX, 2016b).

The MR-MPS-SW reference model defines 7 maturity levels, where each level characterizes the stage where the organization lies about its maturity process in software development, as shown in Table 1. These maturity levels are a combination of the process and its capacity (ARAUJO et al., 2015). Processes are described in MR-MPS-SW in terms of purpose and expected results. 
Table 1. MR-MPS-SW components. Source: SOFTEX (2016b)

\begin{tabular}{|c|c|c|}
\hline Level & Processes & Process Attributes \\
\hline A & & AP 1.1, AP 2.1, AP 2.2, AP 3.1, AP 3.2, AP 4.1, AP 4.2, AP 5.1 and AP 5.2 \\
\hline $\mathrm{B}$ & Project Management (GPR) - Evolution & AP 1.1, AP 2.1, AP 2.2, AP 3.1 e AP 3.2, AP 4.1 and AP 4.2 \\
\hline \multirow[t]{3}{*}{$\mathrm{C}$} & Risk Management (GRI) & AP 1.1, AP 2.1, AP 2.2, AP 3.1 and AP 3.2 \\
\hline & Development for Reutilization (DRU) & \\
\hline & Decision Management (GDE) & \\
\hline \multirow[t]{5}{*}{$\mathrm{D}$} & Verification (VER) & AP 1.1, AP 2.1, AP 2.2, AP 3.1 and AP 3.2 \\
\hline & Validation (VAL) & \\
\hline & Project and Product Construction (PCP) & \\
\hline & Product Integration (ITP) & \\
\hline & Requirements Development (DRE) & \\
\hline \multirow[t]{5}{*}{$\mathrm{E}$} & Project Management (GPR)- Evolution & AP 1.1, AP 2.1, AP 2.2, AP 3.1 and AP 3.2 \\
\hline & Reutilization Management (GRU) & \\
\hline & Human Resources Management (GRH) & \\
\hline & Organizational Processes Definition (DFP) & \\
\hline & Organizational Process Assessment and Improvement (AMP) & \\
\hline \multirow[t]{5}{*}{$\mathrm{F}$} & Measurement (MED) & AP 1.1, AP 2.1 and AP 2.2 \\
\hline & Quality Assurance (GQA) & \\
\hline & Project Portfolio Management (GPP) & \\
\hline & Configuration Management (GCO) & \\
\hline & Acquisition (AQU) & \\
\hline \multirow[t]{2}{*}{$\bar{G}$} & Requirement Management (GRE) & AP 1.1 and $A P 2.1$ \\
\hline & Project Management (GPR) & \\
\hline
\end{tabular}

Table 2. C2M components. Source: Farias Junior (2014)

\begin{tabular}{|c|c|c|c|}
\hline Maturity Area & Maturity Factor & Maturity Level & Practices \\
\hline \multirow[t]{2}{*}{ People } & Cultural Differences Management & 2 and 3 & $\mathrm{CD} 1, \mathrm{CD} 2, \mathrm{CD} 3, \mathrm{CD} 4$ and CD5 \\
\hline & Trust Development & 3 & TDE1, TDE2 and TDE3 \\
\hline \multirow[t]{11}{*}{ Project } & Communication Support Tools & 2 and 3 & $\mathrm{TC} 1, \mathrm{TC} 2$ and TC3 \\
\hline & IT Infrastructure & 2 and 3 & INF1, INF2 and INF3 \\
\hline & Geographic Distance Management & 2 and 3 & GD1, GD2, GD3 and GD4 \\
\hline & Temporal Distance Management & 2 e 3 & TD1, TD2, TD3 and TD4 \\
\hline & Stakeholder Management & 2,3 and 4 & SM1, SM2 and SM3 \\
\hline & Monitoring, Measurement and Analysis & 4 & MA1, MA2 and MA3 \\
\hline & Communication Planning & 2 and 3 & $\mathrm{CP} 1, \mathrm{CP} 2, \mathrm{CP} 3, \mathrm{CP} 4, \mathrm{CP} 5, \mathrm{CP} 6, \mathrm{CP} 7, \mathrm{CP} 8$ and CP9 \\
\hline & Organizational & 4 & $\mathrm{CC} 1, \mathrm{CC} 2, \mathrm{CC} 3$ and $\mathrm{CC} 4$ \\
\hline & Risk Management & 2 and 3 & RM1, RM2, RM3 and RM4 \\
\hline & Communication Standards and Policies & 2 and 3 & PP1 and PP2 \\
\hline & Communication Training & 3 and 4 & $\mathrm{CT} 1, \mathrm{CT} 2, \mathrm{CT} 3$ and CT4 \\
\hline \multirow[t]{2}{*}{ Engineering } & Configuration Management & 3 & $\mathrm{CM} 1, \mathrm{CM} 2$ and $\mathrm{CM} 3$ \\
\hline & Requirements Specification and Elicitation & 2 & ES1 and ES2 \\
\hline
\end{tabular}

The purpose describes the general goal to be achieved and the expected results of the process establish the expected evidence, which must be found in work products produced by the process execution.

In this work, MR-MPS-SW was compared to the C2M model. C2M was proposed in 2014, as a result of a doctoral thesis (FARIAS JUNIOR, 2014). It appeared with the proposal of being a maturity level to support the improvement in the communication of distributed software development teams, constituted based on rigorous scientific methods in its project (FARIAS JUNIOR, 2014). C2M model defines a set of elements (FARIAS JUNIOR et al., 2016; LEITÃO JUNIOR et al., 2017):

- Maturity Area: categories which group related maturity factors.

- Maturity Factor: describes a communication maturity factor identified during the C2M research and elaboration process.

- Maturity Level: a group of maturity factors defined for each level, that is, C2M is defined as a set of factors associated with every maturity level.

- Goal: a short description of the goal to be reached by the maturity factor.

- Practice: an item that must be satisfied to reach an arbitrary objective. Each practice in C2M is associated with a maturity level and implemented by a maturity factor.

Every maturity level at C2M comprehends a group of communication maturity factors. Furthermore, every factor describes a goal and a set of practices, and every practice is directly associated to a maturity level. Moreover, a set of maturity factors states the organization level based on its associated set of practices implemented at the respective level (FARIAS JUNIOR, 2014).

C2M specifies four maturity levels: (1) Casual (or ad hoc); (2) Partially managed; (3) Managed and (4) Reflexive. To reach any level, its criteria must be satisfied, as well as its lower levels must have been reached. C2M resulted in 15 maturity factors and 58 maturity practices, as presented in Table 2. Practices in C2M must be performed by organization unities (or processes) to reach a maturity level (FARIAS JUNIOR, 2014). 


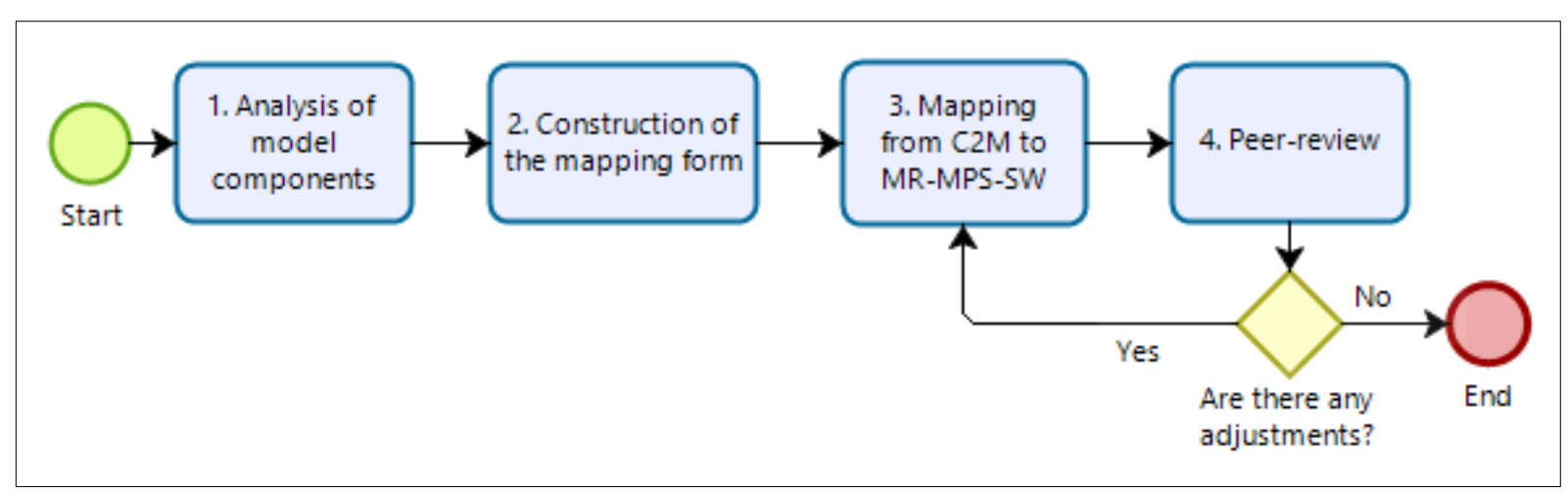

Figure 1. Methodology. Source: Adapted from Mello (2011)

Table 3. Classification criteria. Source: Araujo et al. (2015)

\begin{tabular}{lll}
\hline Code & Name & Description \\
\hline COB & Covered & The origin model covers the requirements of the destiny model. \\
\hline COB- & Partially covered & The origin model covers some or many aspects of the destiny model. \\
\hline NOT & Not covered & The origin model does not cover the require ments of the destiny model. \\
\hline
\end{tabular}

Table 4. Peer review criteria. Source: adapted from Araujo et al. (2015)

\begin{tabular}{lll}
\hline Code & Name & Description \\
\hline TA & High Technical & There was found an issue in an item and, if not altered, it can compromise the considerations. \\
\hline TB & Low Technical & There was found an issue in an item, and it is convenient to change it. \\
\hline E & Editorial & A grammatical error was found or the text must be improved. \\
\hline $\mathrm{Q}$ & Questioning & There were doubts about the content of the considerations. \\
\hline AD & General & General comment related to considerations. \\
\hline
\end{tabular}

\section{RESEARCH METHODOLOGY}

Many studies about the mapping between models have already been made (some of them presented in Section 2), however without a definition of the process used to perform it, making them not replicable (BALDASSARRE et al., 2010). A methodology to map two models was proposed by Mello (2011). This methodology was adapted and applied in other works, such as Araujo et al. (2015) and Garcia et al. (2016). An adaptation of this methodology was also used in this work and encompasses activities presented in Figure 1.

The process presented in Figure 1 divides the execution of this work in four activities:

1. Analysis of the model components: consisted of an analysis of the models mapped by this work, namely MR-MPS-SW and $\mathrm{C} 2 \mathrm{M}$. This analysis focused on understanding the models, their structures and components, to define the comparison format.

2. Construction of the mapping form: aimed in allowing the model components to be described and compared clearly, classifying them according to the criteria defined by Araujo et al. (2015) and shown in Table 3, presenting grounds for the classifications.

3. Mapping from C2M to MR-MPS-SW: In this activity the results expected from C2M (origin model) are compared to the results expected from MR-MPS-SW (destiny model), identifying agreement and disagreement points between them.

4. Peer-review: has as aim to assess the proposed mapping. This review will be performed by specialists in the models, seeking for inconsistencies in the mappings and allowing their corrections. The criteria employed in this step were adapted from Araujo et al. (2015) and are presented in Table 4.

\section{PEER REVIEW}

The mapping was presented to four specialists in software process improvement and, based on criteria established in Table 3, they made their evaluation. Table 5 presents a summary of the reviewers' experience with software process improvement.

From 199 items which compounded the mapping, 88 were considered "Adherent" (AD) by the assessors; in 90 were found problems of the "High technical" (TA) type, and in 21 were found problems of the "Low technical" (TB) type. No problems with the "Editorial" (E), "Questioning" (Q) or "General" (G) type were pointed by the reviewers. All problems from the TA and TB type were corrected. The results, after adjusts, have gone through a member check performed by reviewer 4 (Table 5), aiming to assess the changes performed. According to Sandelowski (2008), member check is a strategy often used to optimize the validity of the results 
Table 5. Reviewers' experience summary. Source: The author

\begin{tabular}{ll}
\hline Reviewer 1 & PhD in Computer Science with 18 years of experience in software process improvement; ISO 9000 assessor; CERTICS assessor; \\
& MPS.BR-SW Implementer and assessor; CMMI-SW implementer; and MPT.BR Implementer and Assessor; C2M full specialist. \\
\hline Reviewer 2 & PhD in Computer Science with 10 years of experience in software process improvement; CERTICS assessor; MPS.BR-SV \\
& Implementer and asses sor; CMMI-Service implementer; and MPT.BR Implementer and Assessor; C2M full specialist. \\
\hline Reviewer 3 & $\begin{array}{l}\text { PhD in Computer Science with } 12 \text { years of experience in software process improvement; MPS.BR-SW and MPS.BR-SV } \\
\text { Implementer; CMMI Service implementer; and MPT.BR Implementer and Assessor; C2M full specialist. }\end{array}$ \\
\hline Reviewer 4 & PhD in Computer Science with 9 years of experience in software process improvement. MPS.BR-SW and MPS.BR-SV \\
& implementer; MPT.BR implementer and assessor; C2M full specialist \\
\hline
\end{tabular}

Table 6. Coverage of the maturity factor CD. Source: the author

\begin{tabular}{|c|c|c|}
\hline C2M & MR-MPS-SW & COVERAGE \\
\hline \multirow[t]{5}{*}{ CD1 - Cultural differences management } & GPR 7 & $\mathrm{COB}$ \\
\hline & GPR 20 (Starting from level E) & $\mathrm{COB}$ \\
\hline & DFP 8 & COB \\
\hline & GRH 2 & $\mathrm{COB}$ \\
\hline & $\begin{array}{l}\text { GRH } 1 \\
\end{array}$ & $\mathrm{COB}$ \\
\hline \multirow[t]{2}{*}{ CD2 - Identifying and institutionalizing the cultural context from each project team } & GRH 9 & COB \\
\hline & GRH 11 & $\mathrm{COB}$ \\
\hline \multirow[t]{2}{*}{ CD3: Establish a cultural knowledge base } & GRH 9 & COB \\
\hline & GRH 11 & $\mathrm{COB}$ \\
\hline CD4: Standardize project jargon and vocabularies & Not covered. & \\
\hline \multirow[t]{2}{*}{ CD5: Planning initiatives to mitigate occurrences caused by cultural differences } & GRI 6 & $\mathrm{COB}$ \\
\hline & GRI 9 & $\mathrm{COB}$ \\
\hline
\end{tabular}

in qualitative researches. The other reviewers could not perform the member check due to availability issues. The results after the member check are presented in the next section.

\section{C2M COVERAGE OF MR-MPS-SW}

The comparison presented in this section was performed between $\mathrm{C} 2 \mathrm{M}$ practices to the results expected from the processes composing the MR-MPS-SW; a mode detailed presentation of these practices and processes can be found in their respective guides: SOFTEX (2016b) and Farias Junior (2014). Details of the mapping are presented in the following sections.

\section{Cultural Difference Management (CD)}

The CD maturity factor, from C2M maturity level 2, is composed of two practices: CD1, which deals with the management of cultural differences; and CD2, which treats the identification and institutionalization of the cultural context. The practice CD1 covers (COB) the expected results GPR7 and GRH2 from MR-MPS-SW, which treat, respectively, of the human resources planning and the recruitment of individuals for the project.

The practice CD1 still presents a partial coverage (COB-) for the expected results GPR20 (from the level E - teams establishment and maintaining from rules and guidelines), DFP8 (establishment and maintaining of rules for team structuring, formation and acting) and GRH1 (review of strategic needs of the organization and projects to identify required resources, knowledge and skills). Practice CD2 covers the expected results GRH11 (knowledge provision and sharing) and covers partially (COB-) the expected result GHR9 (knowledge management strategy planning, establishment and maintaining).

At C2M level 3, the maturity factor CD is composed of more three practices: CD3, which treats the establishment of a cultural knowledge base; CD4, which standardizes the project jargon and vocabularies; and CD5, which plan initiatives to mitigate occurrences caused by cultural differences. The practice CD3 totally covers (COB) the expected results GRH9 (a proper strategy for knowledge management is planned, established and maintained to share information in the organization) and GRH11 (knowledge is made available and shared in the organization).

There was found no expected result in MR-MPS-SW which became close to the practice CD4. In turn, practice CD5 partially covers (COB-) the expected results GRI6 (development of risk mitigation plans) and GRI9 (proper actions are executed to correct or avoid the risk impacts, based on its priority, probability, consequences or other defined parameters). Table 6 resumes the coverage of the maturity factor $C D$.

\section{Trust Development (TDE)}

The maturity factor TDE is present only at level 3 of C2M, and is composed of 3 practices: TDE1, which establishes integration strategies of the stakeholders; TDE2, which treats the member interchange among project dispersed teams; and TDE3, which encourages collaboration and cooperation among teams.

For practice TDE2, there was not found any related item at MR-MPS-SW. In turn, practice TDE1 partially covers (COB-) the expected result GPR 16 (the involvement of the stakeholders in the project is planned, monitored and maintained). Finally, practice TDE3 partially covers (COB-) the expected result GPR 8 - until level F (the resources and workplaces necessary to execute the project are planned). Table 7 consolidates the coverage information about maturity factor TDE. 
Table 7. Coverage of the maturity factor TDE. Source: the author

\begin{tabular}{ll}
\hline C2M & MR-MPS-SW \\
\hline TDE1: Establish strategies for stakeholders' integration. & GPR 16 \\
\hline TDE2: Member interchange among dispersed project teams. & Not covered. \\
\hline TDE3: Encouragement of team collaboration and cooperation. & GPR 8 (Until level F) \\
\hline
\end{tabular}

Table 8. Coverage of the maturity factor TC. Source: the author

\begin{tabular}{ll}
\hline C2M & MR-MPS-SW \\
\hline TC1: Adopt synchronous and/or synchronous on-demand tools. & GPR 8 (Until level F) \\
\hline TC2: Adopt collaboration tools & GPR 8 (until level F) \\
\hline TC3: Adopt face-to-face communication tools & GPR 8 (Until level F) \\
\cline { 2 - 2 } & GPR 8 (Until level E) \\
\cline { 2 - 2 } & DFP 7 \\
\hline
\end{tabular}

Table 9. Coverage of the maturity factor INF. Source: the author

\begin{tabular}{ll}
\hline C2M & MR-MPS-SW \\
\hline INF1 - Define infrastructure considering the dispersion level of the team & GPR 8 (Until level F) \\
\hline INF2 - Periodically monitor the infrastructure & GPR 14 \\
\hline INF3 - Maintain a backup infrastructure & $\frac{\text { GPR 8 (Until level F) }}{$\cline { 2 - 2 } \text {$GPR 8 (From level E) }}$ \\
\cline { 2 - 2 } & $\frac{\text { GPR 14 COB }}{\text { DFP } 7}$ \\
\hline
\end{tabular}

\section{Communication Support Tools (TC)}

The maturity factor TC, at C2M level 2, is composed of two practices, TC1 and TC2, which deal with the adoption of communication and collaboration tools. Both practices (TC1 and TC2) partially cover (COB-) the expected result GPR8 (resource and workplace planning).

At level 3, the maturity factor TC is composed also of the practice TC3, which focuses on the adoption of face-to-face tools. TC3 partially covers (COB-) the expected results GPR 8 - until level F (resources and workplaces necessary to execute the project are planned), GPR 8 - from level E (resources and workplaces necessary to execute the project are planned, starting from standard workplaces of the organization) and DFP 7 (standard workplaces of the organization are established and maintained). Table 8 shows the coverage of the maturity factor $C D$.

\section{IT Infrastructure (INF)}

The maturity factor INF, at level 2 of C2M, is composed of the practices INF1 (define the infrastructure considering the dispersion level of the team) and INF2 (periodically monitor the infrastructure). INF1 covers (COB) the expected result GPR8 (resource planning and workplaces). INF2 partially covers (COB-) the expected result GPR14, which approaches the monitoring of material and human resources and relevant data of the project.

At level 3, the maturity factor INF is composed also of the practice INF3, which focuses on the maintaining of backup infrastructure. this practice partially covers (COB-) the expected results GPR 8 - until level F (resources and workplaces needed to execute the project are planned), GPR 8 - from level E (material and human resources, as well as relevant project data, are monitored in relation to the planned), GPR 14 (material and human resources, as well as relevant project data, are monitored in relation to the planned) and DFP 7 (the default workplaces of the organization are established and maintained). Table 9 presents in a summarized form, the coverage of the maturity factor INF.

\section{Geographic Distance Management (GD)}

The maturity factor GD is composed, at C2M level 3, of two practices: GD1 (planning and face-to-face meetings) and GD2 (plan and execute frequent communication). There was not found anything similar to the factor GD1 at the expected results of the MRMPS-SW.

The practice GD2 partially covers (COB-) three expected results: MED7 (communication of the data resulting from analysis), GRH9 (planning, establishment, and maintaining of a knowledge management strategy) and GRH11 (knowledge provision and sharing).

At level 4, the maturity factor GD is composed of two more practices: GD3, which deals with the establishment of a discussion forum in the project; and GD4, which plan initiatives to mitigate occurrences caused by geographic distance. The practice GD3 partially covers (COB-) the expected results GRH10 (a network of experts in the organization is established and a mechanism to support the information exchange between experts and projects is implemented) and GRH11 (knowledge is made available and shared in the organization). While the practice GD4 totally covers (COB) the expected result GRI 6 (risk mitigation plans are developed), and presents a partial coverage (COB-) for the expected result GRI 9 (proper actions are executed to correct or avoid the risk impact, based on its priority, probability, consequence or other defined parameters). Table 10 consolidates the information about the coverage of the maturity factor GD. 
Table 10. Coverage of the maturity factor GD. Source: the author

\begin{tabular}{ll}
\hline C2M & MR-MPS-SW \\
\hline GD1 - Plan face-to-face meetings & Not covered. \\
\hline GD2 - Plan and execute frequent communication & MED 7 \\
\cline { 2 - 2 } & GRH 9 9 \\
\hline GD3 - Establish a discussion forum in the project & COB \\
\cline { 2 - 2 } & GRH 10 10 \\
\hline GD4 - Plan initiatives to mitigate occurrences caused by geographic distance 11 \\
\hline
\end{tabular}

Table 11. Coverage of the maturity factor TD. Source: the author

\begin{tabular}{ll}
\hline C2M & MR-MPS-SW \\
\hline TD1 - Plan and manage the team synchronization schedules & Not covered. \\
\hline TD2 - Plan and execute the continuity of the tasks (transference) & Not covered. \\
\hline TD3 - Plan and manage the follow-the-sun strategy (almost continuous development) & $\frac{\text { GPR10 }}{\text { GPR8 (Until level F) }}$ \\
\hline TD4 - Plan initiatives to mitigate occurrences caused by temporal distance & $\frac{\text { GRI } 6}{\text { GRI } 9}$ \\
\hline
\end{tabular}

Table 12. Coverage of the maturity factor SM. Source: the author

\begin{tabular}{lll}
\hline C2M & MR-MPS-SW & COVERAGE \\
\hline SM1: Identify the stakeholders & GPR 16 & COB \\
\hline SM2: Define roles and responsibilities & GPR 16 & COB \\
\cline { 2 - 3 } & GPP 3 & COB \\
\hline SM3: Plan the stakeholder management & GPR 16 & COB \\
\hline SM4: Monitor the stakeholders' relationship & GPR 16 & COB \\
\hline
\end{tabular}

\section{Temporal Distance Management (TD)}

The maturity factor TD, at level 2 of C2M, is composed of two practices: TD1, which treats of planning and management of the team synchronization schedules, and TD2, which deals with planning and execution of the continuity of the tasks (transference). MR-MPS SW does not have expected results that correspond to these two practices of the factor TD.

At C2M level 3, the maturity factor TD has two more practices: TD3 (plan and manage the follow-the-sun strategy) and TD4 (plan initiatives to mitigate occurrences caused by temporal distance). Practice TD3 partially covers (COB-) the expected results GPR10 (a general plan to execute the project is established with the integration of specific plans) and GPR8 - until level F (resources and workplaces necessary to execute the project are planned). In turn, practice TD4 presents total coverage (COB) for the expected result GRI 6 (plans for risk mitigation are developed), and partially covers (COB-) the expected result GRI 9 (proper actions are executed to correct or avoid the risk impact, based on its priority, probability, consequence or other defined parameters). Table 11 summarizes the coverage of the maturity factor TD.

\section{Stakeholders Management (SM)}

The maturity factor SM, at C2M level 2, also is composed of two practices, SM1 and SM2, which treat, respectively, of the identification of stakeholders and the definition of roles and responsibilities. Either partially cover (COB-) the practice GPR16, which deals with planning, monitoring and maintaining the stakeholders' involvement. SM2 also totally covers (COB) the expected result GPP3 which deals with the establishment of esponsibility and authority in the project management.

At C2M level 3, the maturity factor SM presents one more practice: SM3 (plan the stakeholder management). SM3 totally covers (COB) the expected result GPR 16 (the involvement of the stakeholders in the project is planned, monitored and maintained). Finally, at level 4, one more practice is added to the maturity factor SM: SM4, which deals with monitoring the stakeholders' relationship. SM4 totally covers the expected result GPR 16 (the involvement of the stakeholders in the project is planned, monitored and maintained). Table 12 presents, in a summarized form, the coverage of the maturity factor SM.

\section{Monitoring Measurement and Analysis (MA)}

The maturity factor MA is composed of three practices, all contemplated at C2M level 4: MA1, which establishes the measurement objectives; MA2, which establishes procedures to gather, store and analyze data; and MA3, which deals with the communication of the measurement results. The practice MA1 totally covers (COB) the expected result MED 1 (measurement objectives are established and maintained from the business objectives of the organization and the information needs of technical and management processes). On its turn, the practice MA2 totally covers (COB) the expected results MED 5 (the required data are collected and analyzed) and MED 7 (data and results from the analysis are communicated to the stakeholders and used to support decisions). The practice MA3 totally covers the expected result MED 7 (data and results from the analysis are communicated to stakeholders and used to support decisions). Table 13 presents, in a summarized form, the coverage of the maturity factor MA. 
Table 13. Coverage of the maturity factor MA. Source: the author

\begin{tabular}{ll}
\hline C2M & MR-MPS-SW \\
\hline MA1: Establish the measurement objectives. & MED 1 \\
\hline MA2: Establish procedures to gather, store and analyze data. & MED 5 \\
\cline { 2 - 2 } & MED 7 \\
\hline MA3: Communicate the measurement results. & MED 7 \\
\hline
\end{tabular}

Table 14. Coverage of the maturity factor CP. Source: the author

\begin{tabular}{|c|c|c|}
\hline $\mathrm{C2M}$ & MR-MPS-SW & COVERAGE \\
\hline \multirow[t]{3}{*}{ CP1: Establish communication strategies } & GPR 16 & $\mathrm{COB}$ \\
\hline & GRH 9 & COB \\
\hline & GRH 11 & $\mathrm{COB}$ \\
\hline \multirow[t]{2}{*}{ CP2: Establish mechanisms to confirm the understanding of the activities. } & GRE 1 & $\mathrm{COB}$ \\
\hline & GRE 2 & COB \\
\hline CP3: Establish a language standard for the project & Not covered. & \\
\hline \multirow[t]{2}{*}{ CP4: Establish a communication plan } & GPR 10 & $\mathrm{COB}$ \\
\hline & GPR 16 & $\mathrm{COB}$ \\
\hline \multirow[t]{2}{*}{ CP5: Establish the commitment of the stakeholders to the communication planning } & GPR 12 & COB \\
\hline & GPR 16 & $\mathrm{COB}$ \\
\hline CP6: Define a communication focal point (communication interlocutor) & Not covered. & \\
\hline \multirow[t]{4}{*}{ CP7: Project Data (artifacts) management } & GPR 9 & COB \\
\hline & GCO 1 & $\mathrm{COB}$ \\
\hline & GCO 2 & COB \\
\hline & GCO 6 & COB \\
\hline CP8: Periodically communicate information about the project and team performance. & MED 7 & $\mathrm{COB}$ \\
\hline CP9: Plan and manage meetings. & GPR17 & $\mathrm{COB}$ \\
\hline
\end{tabular}

\section{Communication Planning (CP)}

The maturity factor $\mathrm{CP}$ is composed, at C2M level 2, of the following practices: CP1(establish a communication strategy), CP2 (establish mechanisms to confirm the data understanding), CP3 (establish a language standard for the project), CP4 (establish a communication plan), CP5 (establish the commitment of the stakeholders with the communication planning), CP6 (define a communication focus point), and CP7 (project data management).

No expected results which get close to the practices CP3 and CP6 were found at MR-MPS-SW. Practice CP1 partially covers (COB-) the expected results GPR16 (planning, monitoring, and maintaining of the stakeholders), GRH9 (planning, establishment, and maintaining of a knowledge management strategy) and GRH11 (knowledge provision and sharing).

The practice $\mathrm{CP} 2$ covers (COB) the expected result GRE1 (obtaining the understanding of requirements together with suppliers), and partially covers (COB-) the expected result GRE2 (requirements evaluation based on criteria and obtaining of a technical team with requirements). Practice CP4 totally covers (COB) the expected result GPR10 (establishment of a general plan for project execution), and partially covers (COB-) the practice GPR16 (planning, monitoring e maintaining of the stakeholders involvement). Practice CP5 covers (COB) the expected result GPR12 which deals with revision and obtaining of commitment with project plans, and partially covers (COB-) the expected result GPR16 (planning, monitoring, and maintaining of the stakeholders' involvement). Finally, practice CP7 totally covers the following expected results: GPR9 (identification and planning about the way to gather relevant data for the project), GCO1 (establishment and maintaining of a configuration management system), GCO2 (identification of configuration items) and GCO6 (control of storage, handling and release of configuration items and baselines).

At C2M level 3, the maturity factor CP presents two more practices: CP8, which deals with periodical communication of information about the project and team performance, and CP9, which deals with planning and management of meetings. The practice CP8 partially covers (COB-) the expected result MED 7 (analysis data and results are communicated to stakeholders and used to support decisions). While practice CP8 presents total coverage (COB) for the expected result GPR17 (reviews are carried out in project milestones and as established in the planning). Table 14 consolidates the information about the coverage of the maturity factor $\mathrm{CP}$.

\section{Continuous Communication Improvement (CC)}

Maturity factor $\mathrm{CC}$ has four practices, all met at $\mathrm{C} 2 \mathrm{M}$ level 4: $\mathrm{CC} 1$, which deals with data gathering; $\mathrm{CC}$, which provides orientation for use of historical data (establish reliable estimations), CC3, which deals with research, evolution and monitoring of new processes, methods and tools to apply in the organization; and CC4, which establishes, monitors and maintain a strategic plan to improve the communication in the organization.

Practice CC1 totally covers (COB) the expected results: MED 5 (the required data are collected and analyzed) and MED 7 (data and results from the analysis are communicated to stakeholders, and used to support decisions). Practice CC2 partially covers (COB-) the expected results: GPR 4 - until level F (effort and cost to execute tasks and work products are estimated based in historical data or technical references) and GPR 4 - Starting from level E (project tasks planning and estimations are made according to repository estimations and organizational process assets). Practice CC3 totally covers (COB) the expected result AMP 6 (a process improvement implementation plan is defined and executed, and the effects of this implementation are monitored 
Table 15. Coverage of the maturity factor CC. Source: the author

\begin{tabular}{|c|c|c|}
\hline $\mathrm{C2M}$ & MR-MPS-SW & COVERAGE \\
\hline \multirow[t]{2}{*}{ CC1: Execute the data gathering } & MED 5 & $\mathrm{COB}$ \\
\hline & MED 7 & COB \\
\hline \multirow[t]{2}{*}{ CC2: Provide orientation for the use of historical data (establish reliable estimations) } & GPR 4 (Until level F) & $\mathrm{COB}$ \\
\hline & GPR 4 (Until level E) & COB \\
\hline CC3: research, evolution, and monitoring of new processes, methods and tools to apply in the organization. & AMP 6 & $\mathrm{COB}$ \\
\hline CC4: Establish, monitor and maintain a strategic action plan to improve communication in the organization & AMP 6 & COB \\
\hline
\end{tabular}

Table 16. Coverage of the maturity factor RM. Source: the author

\begin{tabular}{|c|c|c|}
\hline $\mathrm{C} 2 \mathrm{M}$ & MR-MPS-SW & COVERAGE \\
\hline \multirow[t]{5}{*}{ RM1: Identify communication risks } & GPR 6 & $\mathrm{COB}$ \\
\hline & GRI 3 & $\mathrm{COB}$ \\
\hline & GRI 4 & $\mathrm{COB}$ \\
\hline & GRI 6 & $\mathrm{COB}$ \\
\hline & GRI 7 & $\mathrm{COB}$ \\
\hline \multirow[t]{6}{*}{ RM2: Evolution, categorization and prioritization of communication risks. } & GPR 6 & $\mathrm{COB}$ \\
\hline & GRI 2 & $\mathrm{COB}$ \\
\hline & GRI 3 & $\mathrm{COB}$ \\
\hline & GRI 4 & $\mathrm{COB}$ \\
\hline & GRI 5 & $\mathrm{COB}$ \\
\hline & GRI 7 & $\mathrm{COB}$ \\
\hline RM3: Identification of relevant stakeholders as sociated with all risks. & GRI4 & $\mathrm{COB}$ \\
\hline \multirow[t]{2}{*}{ RM4: Elaborate risk mitigation plan. } & GRI 6 & $\mathrm{COB}$ \\
\hline & GRI 9 & $\mathrm{COB}$ \\
\hline
\end{tabular}

and confirmed according to the improvement goals). And, finally, practice CC4 totally covers (COB) the expected result AMP 6 (an process improvement implementation plan is defined and executed, and the effects of this implementation are monitored and confirmed according to the improvement goals). Table 15 consolidates information about the coverage of the maturity factor CC.

\section{Risks Management (RM)}

Maturity factor RM is composed, at C2M level 2, of practices RM1 (identify communication risks), RM2 (evolution, categorization, and prioritization of communication risks) and RM3 (identify relevant stakeholders associated with the risks). Practice RM1 partially covers (COB-) the expected result GRI3 which approaches the definition and implementation of strategies for risk management.

The practice RM1 still presents a total coverage (COB) for the following expected results: GPR6 (identification of risks, their impacts, occurrence probability, and treatment priority), GRI4 (risk identification and documentation), GRI6 (development of mitigation plans) and GRI7 (analysis and definition of the application priority of resources for risks). The practice RM2 covers (COB) the expected results GRI2 (determination of the origins and categorization of the risks and definition of parameters to analyze risks), GRI4 (risks identification and documentation) and GRI7 (analysis and definition of priority in the application of resources for risks). The practice RM2 also presents partial coverage (COB-) for the expected results GPR6 (identification of risks, their impacts, probability of occurrence and treatment priority), GRI3 (definition and implementation of strategies for risk management), GRI5 (risk prioritization, estimation e classification). Finally, practice RM3 has partial coverage (COB-) for the expected result GRI4 (identification and documentation of project risks).

At C2M level 3, the maturity factor RM presents one more practice: RM4, which deals with the elaboration of a risk mitigation plan. RM4 totally covers (COB) the expected result GRI 6 (plans for risk mitigation are developed). RM4 presents partial coverage (COB-) for the expected result GRI 9 (proper actions are executed to correct or avoid the risk impact, based on its priority, probability, consequence or other defined parameters). Table 16 presents, in a summarized way, the coverage of the maturity factor RM.

\section{Communication Patterns and Policies (PP)}

The maturity factor PP, at level 2 of C2M, is composed of only one practice: PP1, which establishes a communication policy. PP1 does not present coverage for any result expected from MR-MPS-SW.

At C2M level 3, the factor PP presents one more practice: PP2, which establishes documentation and communication standards. PP2 presents partial coverage (COB-) for the expected results, GPR16 (the stakeholders' involvement in the project is planned, monitored and maintained), GPR22 (a process defined for the project is established according to the strategy for adapting the organization's process) e DFP1 (a defined set of standard processes is established and maintained, together with the indication of applicability of every process). Table 17 shows, in a summarized way, the coverage of the maturity factor PP. 
Table 17. Coverage of the maturity factor PP. Source: the author

\begin{tabular}{ll}
\hline C2M & MR-MPS-SW \\
\hline PP1: Establish a communication policy & Not covered. \\
\hline PP2: Establish documentation and communication standards. & $\frac{\text { GPR16 }}{\text { GPR22 }}$ \\
\cline { 2 - 2 } & DFP1 \\
\hline
\end{tabular}

Table 18. Coverage of the maturity factor CT. Source: the author

\begin{tabular}{ll}
\hline C2M & MR-MPS-SW \\
\hline CT1: Plan communication training. & $\frac{G R H 3}{G R H 4}$ \\
\cline { 2 - 2 } & GRH 5 \\
\hline CT2: Provide communication training. & GRH 6 \\
\hline CT3: Register communication training. & GRH 6 \\
\hline CT4: Evaluate the benefits of communication training. & GRH 7 \\
\hline
\end{tabular}

\section{Communication Training (CT)}

The maturity factor $\mathrm{CT}$ is composed, at level 3, of three practices: CT1, which deals with the planning of communication training; CT2, which provides communication training; and CT3, which deals with the register of training in communication. The practice $\mathrm{CT} 1$ presents total coverage (COB) for the expected results, GRH 3 (the training activities needs which are responsibility of the organization are identified), GRH 4 (A training strategy is defined, aiming to meet the training requirements of the projects and organization) and GRH 5 (a tactical training plan is defined, aiming to implement the training strategy). The practice CT2 totally covers (COB) the expected result GRH 6 (training activities identified as a responsibility of the organization are conducted and registered). And, finally, practice $\mathrm{CT} 3$ totally covers (COB) the expected result GRH 6 (training activities identified as a responsibility of the organization are conducted and registered).

At C2M level 4, maturity factor CT has one more practice: CT4 (evaluate the benefits of communication training). CT4 totally covers (COB) the expected result GRH 7 (training effectiveness is evaluated). Table 18 summarizes the coverage of the maturity factor $\mathrm{CT}$.

\section{Configuration Management (CM)}

All practices of the maturity factor CM are part of level 3 in the $\mathrm{C} 2 \mathrm{M}$. These are CM1, which establishes the control of versions and modifications; $\mathrm{CM} 2$, which establishes the access control to configuration items; and CM3, which establishes a configuration plan for the whole project.

The practice CM1 totally covers (COB) the following expected results: GCO 1 (A Configuration Management System is established and maintained), GCO 2 (the configuration items are identified with basis in established criteria), GCO 3 (configuration items subject to formal control are put under baseline), GCO 5 (modifications in configuration items are controlled) and GCO 7 (configuration audits are objectively performed to ensure that baselines and configuration items are complete and consistent). The practice CM1 still presents partial coverage (COB-) for the expected result GCO 4 (the situation of configuration items and baselines is registered along the time and made available).

The practice CM2 partially covers (COB-) the expected result GPR 9 (relevant project data are identified and planned according to the gathering, storage and distribution ways. A mechanism is established to access them, including, if applicable, privacy, and security questions). CM2 still covers partially (COB-) the expected result GCO 6 (storage, handling, and liberation of configuration items and baselines are controlled).

Finally, the practice CM3 partially covers (COB-) the expected results: GPR 9 (relevant data of the project are identified and planned regarding the ways of gathering, storage and distribution. A mechanism is established to access them, including, if applicable, privacy and security questions), and GCO 1 (a Configuration Management System is established and maintained). The practice CM3 still presents total coverage (COB) for the expected results: GPR 10 (a general plan for the project execution is established with the integration of specific plans), GCO 2 (configuration items are identified based on established criteria) and GCO 4 (the situation of configuration items and baselines is registered along the time and made available). Table 19 presents, in a summarized way, the coverage of the maturity factor $\mathrm{CM}$. 
Table 19. Coverage of the maturity factor CM. Source: the author

\begin{tabular}{|c|c|c|}
\hline $\mathrm{C} 2 \mathrm{M}$ & MR-MPS-SW & COVERAGE \\
\hline \multirow[t]{6}{*}{ CM1: Establish the control of versions and modifications. } & GCO 1 & $\mathrm{COB}$ \\
\hline & $\mathrm{GCO} 2$ & $\mathrm{COB}$ \\
\hline & $\mathrm{GCO} 3$ & $\mathrm{COB}$ \\
\hline & $\mathrm{GCO} 4$ & $\mathrm{COB}$ \\
\hline & GCO 5 & $\mathrm{COB}$ \\
\hline & $\mathrm{GCO} 7$ & $\mathrm{COB}$ \\
\hline \multirow[t]{2}{*}{ CM2: Establish the access control to configuration items. } & GPR 9 & $\mathrm{COB}$ \\
\hline & GCO 6 & $\mathrm{COB}$ \\
\hline \multirow[t]{5}{*}{ CM3: Establish a configuration plan for the whole project. } & GPR 9 & $\mathrm{COB}$ \\
\hline & GPR 10 & $\mathrm{COB}$ \\
\hline & GCO 1 & $\mathrm{COB}$ \\
\hline & $\mathrm{GCO} 2$ & $\mathrm{COB}$ \\
\hline & $\mathrm{GCO} 4$ & $\mathrm{COB}$ \\
\hline
\end{tabular}

Table 20. Coverage of the maturity factor ES. Source: the author

\begin{tabular}{|c|c|c|}
\hline $\mathrm{C} 2 \mathrm{M}$ & MR-MPS-SW & COVERAGE \\
\hline \multirow[t]{6}{*}{ ES1: Obtain confirmation of the software requirements understanding by the team. } & GRE 1 & $\mathrm{COB}$ \\
\hline & GRE 2 & $\mathrm{COB}$ \\
\hline & DRE 7 & $\mathrm{COB}$ \\
\hline & VAL 1 & $\mathrm{COB}$ \\
\hline & VAL 2 & $\mathrm{COB}$ \\
\hline & VAL 3 & $\mathrm{COB}$ \\
\hline ES2: Manage the changes in software requirements & GRE 5 & $\mathrm{COB}$ \\
\hline ES3: Maintain the traceability of software requirements. & GRE 3 & $\mathrm{COB}$ \\
\hline
\end{tabular}

Requirements Specification and Elicitation (ES)

The maturity factor ES, at level 2 of C2M, is composed of two practices: ES1 (obtain confirmation of the understanding of software requirements by the team) and ES2 (manage changes in software requirements).

The practice ES1 presents coverage (COB) for the following expected results: GRE1 (obtaining of requirement understanding together with requirement suppliers), DRE7 (requirements validation) and VAL1 (identification of work products to be validated). The practice ES1 still presents partial coverage (COB-) for the expected results GRE2 (requirement evaluation based in objective criteria and obtaining of team commitment with requirements), VAL2 (implementation of a validation strategy) and VAL3 (identification of criteria and procedures to evaluation and establishment of a validation environment). The practice ES2 totally covers (COB) the expected result GRE5 (management of requirement changes during the project).

At C2M level 3, the maturity factor ES presents one more practice: ES3, which deals with the maintaining of the software requirements traceability. ES3 totally covers the expected result GRE 3 (bidirectional traceability between requirements and work products is established and maintained). Table 20 summarizes the coverage of the maturity factor ES.

\section{Overview of the Mapping}

The performed mapping allowed to identify that $82,2 \%$ of the C2M practices present some kind of coverage for the results expected from MR-MPS-SW. Only the practices GD1, TD1, TD2, CP3, CP6, PP1, CD4 and TDE2 from C2M do not present coverage for MR-MPS-SW. Table 21 presents the mapping in a summarized way. 
Table 21. Summary of the C2M in relation to MR-MPS-SW

\begin{tabular}{|c|c|c|c|c|c|c|c|c|}
\hline C2M & MR-MPS-SW & & $\mathrm{C} 2 \mathrm{M}$ & MR-MPS-SW & & $\mathrm{C} 2 \mathrm{M}$ & MR-MPS-SW & \\
\hline \multirow{2}{*}{ CD1 } & GPR 7, GRH 2 & $\mathrm{COB}$ & CD3 & GRH 9, GRH 11 & $\mathrm{COB}$ & $\mathrm{CC} 1$ & MED 5, MED 7 & $\mathrm{COB}$ \\
\hline & GPR 20 (From level E on), DFP 8, GRH 1 & COB- & CD4 & - & - & $\mathrm{CC} 2$ & GPR 4 & $\mathrm{COB}$ \\
\hline \multirow{2}{*}{ CD2 } & GRH 11 & $\mathrm{COB}$ & CD5 & GRI 6, GRI 9 & COB- & $\mathrm{CC} 3$ & AMP 6 & $\mathrm{COB}$ \\
\hline & GRH 9 & COB- & $\mathrm{TC3}$ & GPR 8, DFP 7 & COB- & $\mathrm{CC} 4$ & AMP 6 & $\mathrm{COB}$ \\
\hline TC1 & GPR 8 (Until level F) & COB- & INF3 & GPR 8, GPR 14, DFP 7 & COB- & MA1 & MED 1 & $\mathrm{COB}$ \\
\hline TC2 & GPR 8 (Until level F) & COB- & GD3 & GRH 10, GRH 11 & COB- & MA2 & MED 5, MED 7 & $\mathrm{COB}$ \\
\hline INF1 & GPR 8 (Until level F) & $\mathrm{COB}$ & \multirow{2}{*}{ - GD4 } & GRI 6 & $\mathrm{COB}$ & MA3 & MED 7 & $\mathrm{COB}$ \\
\hline INF2 & GPR 14 & COB- & & GRI 9 & COB- & SM4 & GPR 16 & $\mathrm{COB}$ \\
\hline GD1 & - & - & TD3 & GPR10, GPR8 (Until level F) & COB- & $\mathrm{CT} 4$ & GRH 7 & $\mathrm{COB}$ \\
\hline GD2 & MED 7, GRH 9, GRH 11 & COB- & \multirow{2}{*}{ - TD4 } & GRI 6 & $\mathrm{COB}$ & & & \\
\hline TD1 & - & - & & GRI 9 & $\mathrm{COB}$ & & & \\
\hline TD2 & - & - & SM3 & GPR 16 & $\mathrm{COB}$ & & & \\
\hline SM1 & GPR 16 & COB- & CP8 & MED 7 & $\mathrm{COB}$ & & & \\
\hline \multirow{2}{*}{ SM2 } & GPR 16 & COB- & CP9 & GPR17 & $\mathrm{COB}$ & & & \\
\hline & GPP 3 & $\mathrm{COB}$ & \multirow{2}{*}{ - RM4 } & GRI 6 & $\mathrm{COB}$ & & & \\
\hline CP1 & GPR 16, GRH 9, GRH 11 & COB- & & GRI 9 & $\mathrm{COB}$ & & & \\
\hline \multirow{2}{*}{$\mathrm{CP} 2$} & GRE 1 & $\mathrm{COB}$ & PP2 & GPR16, GPR22, DFP1 & $\mathrm{COB}$ & & & \\
\hline & GRE 2 & COB- & ES3 & GRE 3 & $\mathrm{COB}$ & & & \\
\hline CP3 & - & - & TDE1 & GPR 16 & $\mathrm{COB}$ & & & \\
\hline \multirow{2}{*}{ CP4 } & GPR 10 & COB- & TDE2 & - & - & & & \\
\hline & GPR 16 & $\mathrm{COB}$ & TDE3 & GPR 8 (Until level F) & $\mathrm{COB}$ & & & \\
\hline \multirow{2}{*}{ CP5 } & GPR 12 & $\mathrm{COB}$ & CT1 & GRH 3, GRH 4, GRH 5 & $\mathrm{COB}$ & & & \\
\hline & GPR 16 & COB- & $\mathrm{CT} 2$ & GRH 6 & $\mathrm{COB}$ & & & \\
\hline CP6 & - & - & CT3 & GRH 6 & $\mathrm{COB}$ & & & \\
\hline CP7 & GPR 9, GCO 1, GCO 2, GCO 6 & $\mathrm{COB}$ & \multirow{2}{*}{$-\mathrm{CM} 1$} & $\mathrm{GCO} 1, \mathrm{GCO} 2, \mathrm{GCO} 3, \mathrm{GCO} 5, \mathrm{GCO} 7$ & $\mathrm{COB}$ & & & \\
\hline \multirow{2}{*}{ RM1 } & GPR 6, GRI 4, GRI 6, GRI 7 & $\mathrm{COB}$ & & GCO 4 & $\mathrm{COB}$ & & & \\
\hline & GRI 3 & COB- & \multirow{2}{*}{$-\mathrm{CM} 2$} & GPR 9 & $\mathrm{COB}$ & & & \\
\hline \multirow{2}{*}{ RM2 } & GPR 6, GRI 3, GRI 5 & COB- & & GCO 6 & $\mathrm{COB}$ & & & \\
\hline & GRI 2, GRI 4, GRI 7 & $\mathrm{COB}$ & \multirow{2}{*}{ - CM3 } & GPR 10, GCO 2, GCO 4 & $\mathrm{COB}$ & & & \\
\hline RM3 & GRI4 & COB- & & GPR 9, GCO 1 & $\mathrm{COB}$ & & & \\
\hline PP1 & - & - & & & & & & \\
\hline \multirow{2}{*}{ ES1 } & GRE 1 , DRE 7, VAL 1 & $\mathrm{COB}$ & & & & & & \\
\hline & GRE 2, VAL 2, VAL 3 & $\mathrm{COB}$ & & & & & & \\
\hline ES2 & GRE 5 & $\mathrm{COB}$ & & & & & & \\
\hline
\end{tabular}

Analyzing the mapping results, there is still possible to notice that the following results expected from MR-MPS-SW are covered (partially or totally) by practices found at C2M:

- Project Management Process: GPR 4, GPR6, GPR 7, GPR 8, GPR 9, GPR 10, GPR 12, GPR 14, GPR 16, GPR 17, GPR 20 (from level E on) and GPR 22;

- Process Definition for the Organizational Process (DFP): DFP 1, DFP 7 and DFP 8;

- Human Resources Management Process: GRH 1, GRH 2, GRH 3, GRH 4, GRH 5, GRH 6, GRH 9, GRH 7, GRH 10 and GRH 11 ;

- Measurement Process (MED): MED 1, MED 5 and MED 7;

- Project Portfolio Management Process (GPP): GPP 3;

- Requirement Management Process (GRE): GRE 1, GRE 2, GRE 3 and GRE 5;

- Configuration Management Process (GCO): GCO 1, GCO 2, GCO 3, GCO 4, GCO 5, GCO 6 and GCO 7;

- Risk Management Process (GRI): GRI 2, GRI 3, GRI 4, GRI 5, GRI 6, GRI 7, GRI9 and GRI 14;

- Requirement Development Process (DRE): DRE 7;

- Validation Process (VAL): VAL 1, VAL 2 and VAL 3;

- Organizational Process Evaluation and Improvement Process (AMP): AMP 6.

The building of the mapping also allowed us to identify that does not exist a maturity factor at C2M equivalent to only one MRMPS-SW process. What we can realize at Table 22 is that a maturity factor at C2M is related to more than one MR-MPS-SW process. For all C2M maturity factors, related processes were found at MR-MPS-SW. However, not all C2M practices (which compose the maturity factors), were contemplated in the expected results of the MR-MPS-SW (which compose the processes). Finally, is possible to realize that the mapped models are not conflicting, but complementary, being C2M partially adherent to MR-MPS-SW. 
Table 22. Relationship between C2M maturity factors and MR-MPS-SW processes. Source: the author

\begin{tabular}{|c|c|c|c|}
\hline C2M & & MR-MPS-SW & \\
\hline ABBREVIATION & MATURITY FACTOR & ABBREVIATION & PROCESS \\
\hline \multirow[t]{3}{*}{$C D$} & Management of cultural differences & GPR & Project Management \\
\hline & & $\mathrm{GRH}$ & Human Resources Management \\
\hline & & DFP & Organizational Process Definition \\
\hline $\mathrm{TC}$ & Tools to Support Communication & GPR & Project Management \\
\hline INF & Infrastructure IT & GPR & Project Management \\
\hline \multirow[t]{2}{*}{ GD } & Management of Geographic Distance & MED & Measurement \\
\hline & & GHR & Human Resources Management \\
\hline \multirow[t]{2}{*}{ SM } & Stakeholders Management & GPR & Project Management \\
\hline & & GPP & Projects Portfolio Management \\
\hline \multirow[t]{4}{*}{$\mathrm{CP}$} & Communication Planning & GPR & Project Management \\
\hline & & GRH & Human Resources Management \\
\hline & & GRE & Requirement Management \\
\hline & & GCO & Configuration Management \\
\hline \multirow[t]{2}{*}{ RM } & Risk Management & GPR & Project Management \\
\hline & & GRI & Risk Management \\
\hline \multirow[t]{3}{*}{ ES } & Requirements Elicitation and Specification & GRE & Requirements Management \\
\hline & & DRE & Requirements Development \\
\hline & & VAL & Validation \\
\hline TD & Management of Temporal Distance & No Relationship & \\
\hline $\mathrm{PP}$ & Communication Patterns and Policies & No Relationship & \\
\hline
\end{tabular}

\section{LIMITATIONS AND THREATS}

This work has some limitations and threats. The result of the mapping presented in this work was not implanted in an organization. To overcome this limitation, a revision was performed by experts, seeking to avoid misunderstandings. Another limitation of this work is the fact that the mapping was built unidirectionally, that is, only in the C2M to MR-MPS-SW direction. As an evolution of this research, mapping on the contrary direction is also intended.

Since the C2M model is recent, we had difficulties in obtaining a higher participation from senior specialists in the model to perform a review of the mapping, only one of the four specialists which performed the review of the mapping was a senior specialist in the C2M model, and this can be characterized as a threat to this research. Seeking to minimize risks from this threat, we choose full C2M specialists, with notorious experience in software process improvement, and made available to them material sufficient to understand the $\mathrm{C} 2 \mathrm{M}$ model in its completeness. The senior C2M specialist had a key role in the review, solving many conflicts that surged in the revision of the others.

\section{CONCLUSIONS}

Organizations invest in software process improvement seeking to increase the quality of its products, and, consequently, in augmenting the return from their investments. There are many software process improvement models in the market, with many scopes, and some organizations can find difficulties trying to implement more than on model jointly. In this sense, this work presents a mapping of the process improvement models C2M and MR-MPS-SW.

The most relevant contribution of this work is the confirmation of the adherence of the C2M model to the MR-MPS-SW. In the face of the presented, is possible to confirm the viability of the joint implementation of the two models, without overlapping or prejudice to none of them. The main advantage of the use of this model is to facilitate the implantation of the MR-MPS-SW model in a software company that already has C2M implemented.

The mapping here presented was constructed based on the MR-MPS-SW [SOFTEX 2016b] and C2M [Farias Junior 2014] guides. After built, the mapping was evaluated by four specialists, aiming to identify possible problems. As a result of this evaluation, in $44 \%$ of the items the reviewers agreed with the presented mapping, the other items were adjusted according to the suggestions of the reviewers.

After performing the mapping of the models and the peer-review, it was possible to observe that every C2M maturity factor is related to more than one MR-MPS-SW process and that every maturity factor in C2M has related processes in MR-MPS-SW. However, there are C2M practices that do not cover any expected result of MR-MPS-SW.

$\mathrm{C} 2 \mathrm{M}$ is an emergent maturity model, still in the consolidation phase. The mapping proposed in this work is part of a larger project, which aims to implant and evaluate $\mathrm{C} 2 \mathrm{M}$ in Brazilian software companies, and new results and improvements in the mapping will be found after the ending of the project. 


\section{REFERENCES}

Araujo, L. L., Rocha, A. R. and Santos, G. (2015). MR-MPS-SW e CERTICS: Mapeamento e diretrizes para a implantação conjunta dos modelos. iSys-Revista Brasileira de Sistemas de Informação, 8(2), 34-57. https://doi.org/10.5753/isys.2015.284

Baldassarre, M., Caivano, D., Pino, F., Piattini, M. and Visaggio, G. (2010). A Strategy for Painless Harmonization of Quality Standards: A Real Case. Product-Focused Software Process Improvement, 6156, 395-408. https://doi.org/10.1007/978-3-64213792-1_30

Farias Junior, I. (2014). C2M - A Communication Maturity Model for Distributed Software Development (PhD Thesis). Universidade Federal de Pernambuco.

Farias Junior, I., Marczak, S., Santos, R. and Moura, H. (2016). Communication in Distributed Software Development: A Preliminary Maturity Model. In: IEEE 11th International Conference on Global Software Engineering (ICGSE). pp.164-173. https://doi.org/10.1109/ICGSE.2016.31

Garcia, F., Oliveira, S. and Salviano, C. (2016). CERTICS - A Harmonization with CMMI-DEV Practices for Implementation of Technological Development Competence Area. In: 2016 10th International Conference on the Quality of Information and Communications Technology (QUATIC). pp.119-124. https://doi.org/10.1109/QUATIC.2016.032

Kelemen, Z. (2013). Process Based Unification for Multi-Model Software Process Improvement. Technische Universiteit Eindhoven.

Leitão Júnior, N., Farias Júnior, I., Marczak, S., Santos, R., Furtado, F. and Moura, H. (2017). Evaluation of a Preliminary Assessment Method for Identifying the Maturity of Communication in Distributed Software Development. In: WASHES '17: 2nd Workshop on Social, Human, and Economic Aspects of Software. pp.12-18. https://doi.org/10.1145/3098322.3098326

Mejia, J., Muñoz, E. and Muñoz, M. (2016). Reinforcing the applicability of multi-model environments for software process improvement using knowledge management. Science of Computer Programming, 121, 3-15. https://doi.org/10.1016/j.scico.2015.12.002

Mello, M. (2011). Melhoria De Processos De Software Multi-Modelos Baseada Nos Modelos MPS E CMMI-DEV (Master's thesis). Universidade Federal do Rio de Janeiro.

Mirna, M., Jezreel, M., Giner, A., Jose A., C. and Tom's, S. (2011). Advantages of Using a Multi-model Environment in Software Process Improvement. In: 2011 IEEE Electronics, Robotics and Automotive Mechanics Conference. pp.397-402. https://doi.org/10.1109/CERMA.2011.85

Pardo, C., Pino, F., García, F., Piattini, M. and Baldassarre, M. (2012). An ontology for the harmonization of multiple standards and models. Computer Standards \& Interfaces, 34(1), 48-59. https://doi.org/10.1016/j.csi.2011.05.005

Peldzius, S. and Ragaisis, S. (2011). Comparison of maturity levels in CMMI-DEV and ISO/IEC 15504. Applications of Mathematics and Computer Engineering, pp.117-122.

Sandelowski, M. (2008). Member check. In: L. Given (ed.), The SAGE encyclopedia of qualitative research methods (2nd ed., pp.501502). Sage publications.

Shamsul, S., Aedah Abd, R. and Ibrahim, S. (2012). Multi-Process Quality Model: Identification of Key Processes in the Integration Approach. GSTF Journal on Computing, 2(1), 208-213.

SOFTEX (2012a). MPS.BR - Melhoria De Processo Do Software Brasileiro. Guia De Implementação - Parte 12: Análise Da Aderência Do MRMPS-SW:2012 Em Relação À NBR ISO/IEC 29110-4-1:2012 - Engenharia De Software - Perfis De Ciclo De Vida Para Microorganizações (Vses) - Parte 4-1: Especificações De Perfil: Grupo Perfil Genérico. Sociedade SOFTEX.

SOFTEX (2012b). Guia de implementação parte 13: Mapeamento e sistemas de equivalências entre o MR-MPS-SW:2012 e o MoProSoft:2005. Sociedade SOFTEX.

SOFTEX (2016a). Guia de implementação parte 11: Implementação e avaliação do MR-MPS-SW:2016 em conjunto com o CMMI-DEV v1.3. Sociedade SOFTEX.

SOFTEX (2016b). Guia geral MPS de software. Sociedade SOFTEX.

SOFTEX (2018). Avaliações Vigentes - Softex. [online] Softex. Available at: https://www.softex.br/mpsbr/avaliacoes (Accessed 20 July 2020).

Vieira, J., Ivaldir de, F., Moura, H. and Savio, D. (2020). Comparative Study of the Maturity Models C2M e MR-MPS-SW. In: 2020 15th Iberian Conference on Information Systems and Technologies (CISTI). Pp.1-6. https://doi.org/10.23919/CISTI49556.2020.9141008 